\title{
A comparative review of use of sulphate and phosphate salts for colonoscopy preparations and their potential for nephrotoxicity
}

\section{(ㄷ)(i)}

\author{
Authors \\ Bruno Moulin', Thierry Ponchon² \\ Institutions \\ 1 Nephrology Department, Strasbourg University \\ Hospital, 67091 Strasbourg, France \\ 2 Hepatogastroenterology Department, Edouard Herriot \\ Hospital, 69000 Lyon, France
}

submitted 21.6.2017

accepted after revision 28.11.2017

\author{
Bibliography \\ DOI https://doi.org/10.1055/a-0581-8723 | \\ Endoscopy International Open 2018; 06: E1206-E1213 \\ (c) Georg Thieme Verlag KG Stuttgart · New York \\ ISSN 2364-3722
}

\section{Corresponding author}

Pr. Bruno Moulin, Service de néphrologie et transplantation rénale, CHU de Strasbourg - Nouvel Hôpital Civil, 1, place de l'Hôpital, BP 426, 67091 Strasbourg Cedex, France

Fax: +33 369551721

moulin@unistra.fr

\section{ABSTRACT}

Background and study aims Colonoscopy is a widely used diagnostic procedure which requires prior cleansing of the bowel. Many different bowel cleansing preparations have been developed, all of which have specific advantages and disadvantages. This review compares two low-volume high-osmolarity bowel cleansing preparations, oral phosphate salts and oral sulphate salts, with a particular focus on risk of nephrotoxicity.

Patients and methods An electronic search of the Medline database was performed using the search terms "(phosphates OR sulfates) AND cathartics [MeSH Term] AND kidney" restricted to humans with a cut-off date of December 31, 2016.

Results Introduction of oral phosphate salts offered the advantage of low intake volume and low risk of bowel irritation compared to previous options. However, phosphate salts have been associated with renal toxicity (acute phosphate nephropathy [APN]), thought to arise due to perturbations of calcium and phosphate homeostasis as a consequence of increases in serum phosphate. This results in high concentrations of calcium phosphate in the distal tubule and collecting ducts of the kidney, where it may precipitate. Although APN is rare, it may lead to permanent kidney damage. For this reason, phosphate salts are contraindicated in vulnerable patient groups. As an alternative to phosphate salts, oral sulphate salts have recently been introduced. Because sulphate absorption from the intestinal tract is saturable, serum sulphate concentrations increase only minimally after ingestion. Furthermore, excretion of sulphate in the kidney is not accompanied by calcium excretion and urine calcium levels are unchanged. For these theoretical reasons, use of sulphate salts as bowel cleansing solutions is not expected to lead to calcium precipitation in the nephron.

Conclusions Oral phosphate salts are no longer recommended for routine use as bowel cleansing preparations as they carry significant risk of kidney damage and a safer alternative is available in the form of oral sulphate solutions. To date, use of sulphate salts has not been associated with elevations in serum creatinine or other markers of renal impairment, nor with clinical manifestations of kidney injury. Nonetheless, experience with sulphate salts in everyday practice is limited and physicians should be vigilant in detecting potential safety issues.

\section{Introduction}

Colonoscopy is a widely-used procedure, notably in screening for colorectal cancer. Successful colonoscopy requires a clean bowel empty of all fecal matter and residual fluids. To that end, a number of bowel cleansing preparations have been de- veloped, many of which contain, either exclusively or in combination with laxatives, high-osmolarity electrolyte solutions. However, bowel cleansing preparations containing high concentrations of phosphate have been associated with renal complications. To obviate such complications, newer high-osmolarity electrolyte bowel cleansing preparations have been devel- 
oped containing inorganic anions other than phosphate, notably sulphate salt solutions. This article discusses the mechanisms underlying phosphate-related nephrotoxicity and evaluates the potential of bowel cleansing preparations composed of sulphate salt solutions to impair the kidney.

\section{Patients and methods}

An electronic search of the Medline database was performed using the search terms "(phosphates OR sulfates) AND cathartics [MeSH Term] AND kidney" restricted to humans with a cutoff date of $31^{\text {st }}$ December 2016. This yielded 97 references which were screened manually and the most relevant selected. Further relevant articles cited in the bibliography of these selected references were also identified.

\section{Bowel cleansing preparations: what are the needs and what are the options?}

Effective and safe bowel cleansing preparations are essential for performing satisfactory colonoscopic examination of the large bowel. The European Commission has recently published guidelines for quality assurance in colorectal cancer screening and diagnosis [1]. These state that effective bowel cleansing is fundamental to achieving high quality in endoscopy. Thorough cleansing of the large bowel is the first mandatory step for success, because if the practitioner's vision is obscured, small or flat lesions anywhere in the colon and particularly lesions in the right colon may go undetected [1]. Furthermore, inadequate cleansing of bowel may lead to procedures being cancelled or having to be repeated, thus introducing delays in diagnosis or treatment. In everyday practice, approximately $20 \%$ to $30 \%$ of unsuccessful colonoscopy procedures are due to inadequate bowel preparation $[2,3]$.

\section{Bowel cleansing preparations}

Current approaches to bowel cleansing prior to colonoscopy have significant drawbacks that have not been fully resolved. As stated in the position paper published by the American Society of Colon and Rectal Surgeons (ASCRS), the American Society for Gastrointestinal Endoscopy (ASGE), and the Society of American Gastrointestinal and Endoscopic Surgeons (SAGES) "The ideal preparation for colonoscopy would reliably empty the colon of all faecal material in a rapid fashion with no gross or histologic alteration of the colonic mucosa. The preparation also would not cause any patient discomfort or shifts in fluids or electrolytes and would be inexpensive. Unfortunately, none of the preparations currently available meet all of these requirements" [4].

Available orally administered bowel cleansing preparations include osmotic laxatives, including polyethylene glycol (PEG) solutions and high-osmolarity salt solutions, such as sodium phosphate and sodium sulphate, saline laxatives such as magnesium citrate and sodium picosulphate. Stimulant laxatives such as bisacodyl and senna are also used as adjuncts to osmotic or saline laxatives in certain bowel-cleansing preparations. Practice guidelines from the ASGE [5], dating from 2015, and the 2013 European guidelines [6] both recommend PEG as the first choice of bowel cleansing preparations. Both guidelines state that sodium phosphate should not be used in vulnerable patient groups due to risk of nephrotoxicity.

The effect of polyethylene glycol is to adsorb water from the bowel content leading to retention of fluid and electrolyte in the stool, thus promoting a liquid diarrhea. Although some absorption of polyethylene glycol across the intestinal epithelium occurs, this depends on the molecular weight and, for the high molecular weights used as bowel-cleansing preparations (3350 and $4000 \mathrm{Da})$, this absorption is minimal $[7,8]$. The calculated amount of fluids lost with polyethylene glycol preparations are drunk with the preparation to maintain fluid balance and thus prevent patients from becoming dehydrated and electrolytes are also added to ensure electrolyte balance. Because PEG passes through the bowel without net absorption or secretion and is systematically administered with electrolytes, significant fluid and electrolyte shifts are avoided [4]. However, large volumes of solution (up to $4 \mathrm{~L}$ ) need to be ingested, which is the reason that between $5 \%$ and $40 \%$ of patients do not complete ingestion of the whole amount of preparation. Another constraint is that many polyethylene glycol preparations have a salty taste due to the electrolyte content and an oily texture which certain patients find unpleasant. This impedes ability to complete the preparation and, more importantly, discourages patients from undergoing or repeating a colonoscopy. To overcome these drawbacks, modified PEG preparations combined with saline laxatives allowing smaller volumes to be used have been developed.

Until recently, oral phosphate solutions (OPS) represented the other principal class of recommended bowel cleansing preparations. These high-osmolarity solutions attract water into the colon due to an osmotic effect allowing a copious watery diarrhea. Unlike PEG preparations, only small volumes need to be taken ( $90 \mathrm{~mL}$ for the most widely used preparation), although additional water or other clear fluids, up to a total volume of $3 \mathrm{~L}$, need to be drunk to avoid dehydration, significant electrolyte disturbances and fluid shifts. Nevertheless, due to its specific phosphate salt composition, OPS can lead to significant hyperphosphatemia with a potential risk of acute renal failure or long-term structural kidney damage due to precipitation of calcium phosphate crystals in the kidneys (APN). Identification of this risk has led to reinforcement of the safety warning for these products, which are no longer recommended as the product of choice in North American [5] and European [6] professional practice guidelines. Indeed, following an alert issued by the US Food and Drug Administration, in 2008, OPS were withdrawn from the US market as laxatives and precautions for their use for bowel cleansing have been reinforced with a black box warning.

Since 2013 (2010 in the United States), high-osmolarity sulphate salts (OSS) have been introduced as an alternative to PEG and OPS bowel cleansing preparations [9]. These OSS contain a mixture of sodium, potassium and magnesium sulphates and, like OPS, act by drawing water into the colon through an osmotic effect. Again, they can be administered as low doses (two intakes of $180 \mathrm{~mL}$ ) together with water to avoid dehydration. To date, no major electrolyte disturbances or cases of kid- 
- Table 1 Serum phosphate levels before and after administration of an oral phosphate salt bowel cleansing preparation in subjects with normal renal function.

\begin{tabular}{|c|c|c|c|c|c|c|}
\hline Study & Preparation & $\mathbf{N}$ & $\begin{array}{l}\text { SP pre-dose } \\
\text { (mean; } \mathrm{mg} / \mathrm{dL} \text { ) }\end{array}$ & $\begin{array}{l}\text { Time of sampling } \\
\text { post-dose (h) }\end{array}$ & $\begin{array}{l}\text { SP post-dose } \\
\text { (mean; } \mathrm{mg} / \mathrm{dL} \text { ) }\end{array}$ & $\begin{array}{l}\text { Patients with } \\
\text { SP }>8 \mathrm{mg} / \mathrm{dL}(\%)\end{array}$ \\
\hline $\begin{array}{l}\text { Di Palma et al., } \\
1996[17]\end{array}$ & $\begin{array}{l}\text { Fleet Phospho-Soda } \\
(90 \mathrm{~mL})\end{array}$ & 7 & $3.6 \pm 4.5$ & $\begin{array}{l}2,4,6,9,12,14,16 \\
18,21,24 \mathrm{~h}\end{array}$ & $\begin{array}{l}\text { Peak: } 7.7 \pm 0.8 \\
\text { Range: } 3.6-12.4\end{array}$ & NA \\
\hline $\begin{array}{l}\text { Lieberman et al., } \\
1996 \text { [15] }\end{array}$ & $\begin{array}{l}\text { Fleet } \\
(132 \mathrm{~g})\end{array}$ & 32 & $\begin{array}{l}3.1 \\
\text { (range: } 2.0-4.2 \text { ) }\end{array}$ & $1.5 \mathrm{~h}$ & $\begin{array}{l}6.8 \\
\text { (range: } 3.4-9.4 \text { ) }\end{array}$ & \\
\hline $\begin{array}{l}\text { Gumurdulu et al., } \\
2004 \text { [13] }\end{array}$ & $\begin{array}{l}\text { Fleet Phospho-Soda } \\
(90 \mathrm{~mL})\end{array}$ & & & $4-5 h$ & & \\
\hline $\begin{array}{l}\text { - All patients } \\
\text {. } 25-35 \text { years } \\
\text {. } 36-45 \text { years } \\
\text {. } 46-55 \text { years } \\
\text {. }>55 \text { years }\end{array}$ & & $\begin{array}{l}70 \\
12 \\
23 \\
14 \\
21\end{array}$ & $\begin{array}{l}3.56 \pm 0.51 \\
3.20 \pm 0.97 \\
3.50 \pm 0.80 \\
3.55 \pm 0.77 \\
3.50 \pm 0.49\end{array}$ & & $\begin{array}{l}7.87 \pm 2.16 \\
6.80 \pm 1.22 \\
6.80 \pm 1.10 \\
7.65 \pm 1.14 \\
9.00 \pm 1.73\end{array}$ & $37.1 \%$ \\
\hline $\begin{array}{l}\text { Caswell et al., } \\
2007 \text { [18] }\end{array}$ & $\begin{array}{l}\text { Fleet Phospho-Soda } \\
(90 \mathrm{~mL})\end{array}$ & 24 & $3.33 \pm 0.48$ & $14 \mathrm{~h}$ & $6.86 \pm 0.98$ & NA \\
\hline $\begin{array}{l}\text { Casais et al., } \\
2009[14]\end{array}$ & Fosfo-dom (90 mL) & 100 & $\begin{array}{l}3.74 \pm 0.56 \\
\text { (range: } 2.6-5.7 \text { ) }\end{array}$ & $\begin{array}{l}\text { Immediately prior to } \\
\text { colonoscopy }\end{array}$ & $\begin{array}{l}5.58 \pm 1.10 \\
\text { (range: } 2.6-5.7 \text { ) }\end{array}$ & $\begin{array}{l}\text { NA } \\
(87 \%>\text { ULN })\end{array}$ \\
\hline $\begin{array}{l}\text { Ehrenpreis et al., } \\
2009 \text { [16] }\end{array}$ & $\begin{array}{l}\text { Fleet Phospho-Soda } \\
(90 \mathrm{~mL})\end{array}$ & & & $2 \mathrm{~h}$ & & NA \\
\hline $\begin{array}{l}\text { " Low BMI } \\
\text { - High BMI }\end{array}$ & & $\begin{array}{l}7 \\
7\end{array}$ & $\begin{array}{l}3.6 \pm 0.5 \\
3.7 \pm 0.6\end{array}$ & & $\begin{array}{l}7.8 \pm 0.5 \\
5.1 \pm 0.9\end{array}$ & $28 \%$ \\
\hline
\end{tabular}

ney damage have been observed with OSS. The objective of this review is to compare the handling of sulphate and phosphate ion by the kidney, and to address whether there is any demonstrated or theoretical risk of APN with OSS use.

\section{Anion-based bowel cleansing preparations: what are the risks to the kidney?}

\section{Intestinal ion absorption}

Phosphate salts Phosphate ion is absorbed from the bowel by two different mechanisms, a saturable sodium-dependent active transport mechanism, principally in the small intestine, and passive diffusion, which is non-saturable and dependent on the intraluminal phosphate concentration [10]. Under physiological conditions, the active transport process is the most important and responsible for the majority of dietary phosphate absorption. However, the standard dose of OPS contains around $11 \mathrm{~g}$ of elemental phosphorus ( $35 \mathrm{~g}$ of phosphate ion), representing seven to 10 times the average daily dietary phosphorus intake [11]. Under these conditions, intraluminal phosphate concentrations are extremely high and the non-saturable passive diffusion mechanism allows significant transfer of phosphate from the intestinal lumen to the systemic circulation [10]. As a result, serum phosphate levels can largely exceed the normal range of 2.5 to $4.5 \mathrm{mg} / \mathrm{dL}$ in adults [12] ( Table 1 ) [13-18]. Factors that favor hyperphosphatemia include older age $[13,18]$, low glomerular filtration rate [14] and low body mass $[14,16]$. It should be noted that serum phosphate levels show a pronounced circadian rhythm with peaks at mid-afternoon and shortly after midnight and a nadir early in the morning [12]. For this reason, the time of dosing may influence the degree of hyperphosphatemia observed after OPS administration. It is recommended to respect a large between-dose interval with the second dose early in the morning when OPS are used prior to colonoscopy [19]. Around $20 \%$ of the phosphate ingested in OPS is eliminated through the kidneys. Because phosphate is removed from the organism exclusively by urinary elimination, hyperphosphatemia can be further aggravated in patients with impaired renal function.

With respect to other electrolytes, a number of abnormalities have been associated with OPS, including significant hypokalemia and hypernatremia $[20,21]$. These occur principally as a result of absorption of sodium present in the OPS through the intestinal epithelium in exchange for potassium when fluid intake is insufficient and intraluminal sodium concentration exceeds normal plasma levels [20]. Hypokalemia and hypernatremia are particularly frequent in the elderly [22] and, if severe, may be associated with cardiac rhythm disturbances. Hypokalemia and hypocalcemia may also develop secondary to hyperphosphatemia [20].

Sulphate salts Like phosphate, sulphate ion is absorbed from the bowel both through a saturable active transport mechanism and passive diffusion [23]. While active transport accounts for absorption of the large majority of dietary sulphate, this process saturates at higher luminal sulphate concentra- 
tions, for example after ingestion of OSS, and passive diffusion becomes important. Internationally-agreed normal ranges for serum sulphate have not been established, although levels in fasting adults have been reported to be in the range of 240 to $420 \mu \mathrm{mol} / \mathrm{mL}$ (2.3 to $4.6 \mathrm{mg} / \mathrm{dL}$ ) [24]. Serum sulphate levels increase after meals, notably those with a high protein content ( $57 \%$ increase after a high-protein meal compared to an $11 \%$ increase after a low-protein meal) [25]. Serum sulphate levels also vary over the course of the day, with a circadian variation of around $25 \%$ [26], and with age [24]. After administration of OSS, serum sulphate rises around two-fold and around $20 \%$ of the ingested dose appears in the urine [27]. However, the true fraction of the excreted dose is considerably smaller because this estimation does not take into account basal sulphate excretion [27]. The kidney is the principal route of elimination of sulphate from the circulation, and some increase in serum sulphate levels in subjects with renal impairment has been seen after ingestion of OSS [27], from $5.2 \mathrm{mg} / \mathrm{dL}$ in healthy controls to $5.8 \mathrm{mg} / \mathrm{dL}$ in mild renal impairment and in $7.5 \mathrm{mg} / \mathrm{dL}$ in moderate renal impairment, with corresponding reductions in urinary sulphate concentrations.

Clinically significant electrolyte disturbances have not been reported in the pivotal clinical trials with OSS [28,29] and no signal of increased risk of such disturbances compared to other bowel-cleansing preparations was detected in a post-marketing surveillance study [30]. Nonetheless, because experience with OSS in real-world clinical practice is relatively limited, we should be prudent in claiming that electrolyte disturbances do not occur and vigilant in investigating the risk.

\section{Renal anion handling}

Phosphate salts Regulation of phosphorus excretion by the kidney is the principal mechanism for maintaining phosphate homeostasis and several molecular pathways have been implicated therein. First, when serum phosphate levels are high, phosphotonins are secreted and act on the kidneys through the Klotho proteins to down-regulate sodium-phosphate transporters on the apical surface of epithelial cells in the proximal tubule [31]. This reduces phosphate reabsorption in the proximal tubule and thus leads to phosphaturia. Second, as a consequence of hyperphosphatemia, parathyroid hormone (PTH) release is stimulated and synthesis of 1,25-dihydroxyvitamin $D$ reduced. By binding to its receptors on renal epithelial which interact with the $\mathrm{Na}^{+} / \mathrm{H}^{+}$Exchanger Regulatory Factor (NHERF1,) [32] PTH inhibits activity of the NPt2a and the NPt2c sodiumphosphate cotransporters on the brush border of the apical side of the proximal tubular cell in the kidney [12]. Through this mechanism, elevated serum levels of PTH reduce reabsorption of phosphate in the proximal tubule ( Fig. 1) [33]. Finally, these effects are amplified by the high serum phosphate concentrations on the basolateral side of the tubular epithelium, which decreases the trans-epithelial phosphate gradient that drives transporter activity [34]. Due to inhibition of tubular reabsorption, the changes in urinary phosphate levels after ingestion of OPS solutions can be much larger than the changes in serum levels. Indeed, it has been reported that urine phosphate levels rise to four times normal levels after the first intake of a

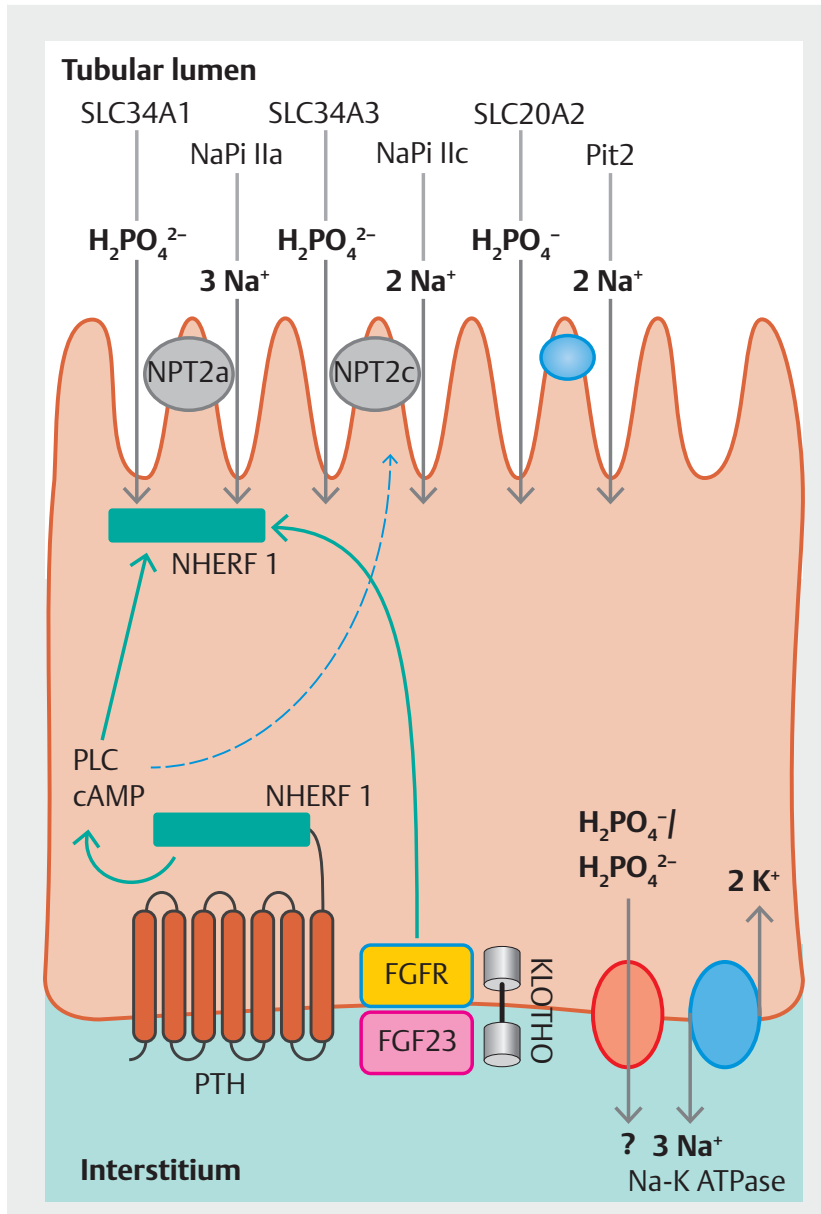

- Fig. 1 Renal transport of phosphate in the proximal tubule.

split-dose OPS preparation and to eight time normal levels after the second intake [35]. These elevations in urinary phosphate persist once serum phosphate has normalised.

Another consequence of hyperphosphatemia is to inhibit calcium reabsorption in the proximal and distal tubule, leading to an increased risk of formation and precipitation of calcium phosphate crystals in the distal tubule and in the collecting duct, where the urine is concentrated. Since high serum phosphate can dramatically increase concentrations of both calcium and phosphate ions, calcium phosphate can precipitate in soft tissues, resulting in hypocalcemia. Indeed several cohort studies have reported reductions in serum calcium levels below the lower limit of normal in patients taking OPS [14,36].

Sulphate salts Because sulphate is freely filtered, the rate of urinary excretion is regulated by the rate of reabsorption and secretion along the proximal tubule. Sulphate is actively transported in the proximal tubule through the luminal brush border membrane and the basolateral membrane of cells. Micropuncture studies have shown that sulphate transport occurs by a sodium-dependent mechanism [37], by sulphate/anion exchange across the brush border of the proximal tubular cell and also by 
a sulphate/anion exchange at the basolateral site of the same cell ( $\triangleright$ Fig. 2).

Only large increases in serum sulphate lead to elevations in urinary calcium excretion, probably due to decreased tubular reabsorption $[38,39]$. However, after administration of OSS, urinary sulphate concentrations increase fourfold whereas urinary calcium concentrations do not increase significantly [35]. Although calcium sulphate is considerably more soluble than calcium phosphate, there is some theoretical risk of precipitation of calcium sulphate in the distal tubule. To test this hypothesis, Patel et al. [35] have compared in healthy volunteers the average calcium concentration required to induce precipitation of urine at the $\mathrm{pH}$ of the distal tubule (6.4) in groups of five subjects treated with one of three different bowel cleansing preparations, namely PEG, OPS and OSS. The threshold calcium concentration for precipitation was $430 \mathrm{mg} / \mathrm{L}$ after PEG, $100 \mathrm{mg} / \mathrm{L}$ after OPS and up to $1870 \mathrm{mg} / \mathrm{L}$ after OSS $(P<0.009)$. This difference could be explained on one hand by a hyper-precipitable state induced by high urinary phosphate after phosphate ingestion and on the other hand by an inhibitory effect of sulphate on calcium-phosphate crystallization. In addition, it is possible that calcium salt deposition is reduced by urinary magnesium, whose concentration is higher after administration of OSS than after OPS $(74 \mathrm{mg} / \mathrm{L}$ versus $23 \mathrm{mg} / \mathrm{L}$, respectively). The authors of this study concluded that hypertonic OSS would be less likely than OPS to produce calcium salt deposition in renal tubules and cause nephrocalcinosis.

\section{Acute kidney injury}

Phosphate salts

Given that hyperphosphatemia in patients using OPS is common, a risk of adverse renal consequences clearly exists, even in patients with normal renal function. Nonetheless, the number of patients in whom documented kidney injury has been described following use of OPS is low, given the extent of use of OPS as bowel cleansing preparations. The first case report suggestive of nephrotoxicity dates from 1975 [40] and cases have been described episodically since then. A review of the available material by Gonlusen et al. in 2011 [41] proposed that two types of kidney injury may be identified following use of OPS. The first, acute type of injury was characterized by signs and symptoms typical of severe hydroelectrolytic abnormalities, which developed hours to a few days after sodium phosphate use. These signs were associated with hyperphosphatemia, hypocalcemia and biological markers of acute renal failure (elevated serum creatinine or urea). In most patients, renal function normalized or improved over the next 30 days. The second pattern of injury [41-45] was detected days and up to 8 weeks after use of OPS when serum phosphate and calcium levels had already normalized, in subjects presenting aspecific signs and symptoms but with abnormal renal function markers. Renal biopsies performed in these patients revealed nephrocalcinosis, characterized by diffuse tubular calcification reflecting acute phosphate nephropathy (APN) [46]. Renal function remained impaired or even deteriorated over time in these patients.

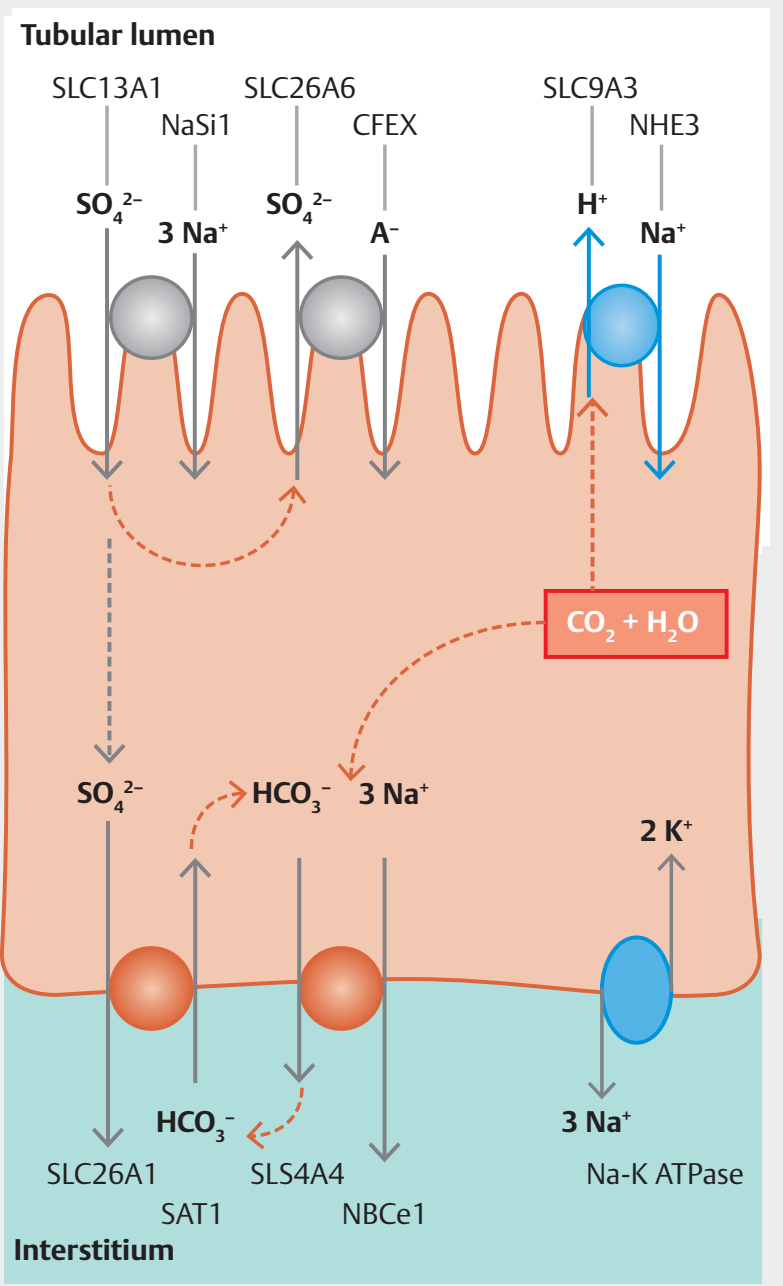

- Fig.2 Renal transport of sulphate in the proximal tubule.

Patients at increased risk of APN may include the elderly, women, individuals with low body weight, patients presenting with hypovolemia, increased bowel transit time (such as bowel obstruction), active colitis, diabetes mellitus, or preexisting kidney disease, and those using medicines that affect renal perfusion or function (such as diuretics, angiotensin converting enzyme inhibitors or angiotensin receptor blockers, and nonsteroidal anti-inflammatory drugs) $[19,20,47,48]$. Nonetheless, cases of APN have been described in patients without identified risk factors.

A number of retrospective and prospective studies have evaluated risk of impaired kidney function in cohorts of patients using OPS as a bowel cleansing preparation with inconsistent results $[19,49]$. The largest of these [50] compared 6,432 patients using OPS to 3,367 using PEG and found that use of OPS was associated with an increase in risk of acute kidney injury, defined as an increase of $\geq 50 \%$ in baseline serum creatinine, in patients using OPS with an odds ratio of $2.35[95 \% \mathrm{Cl}$ : 1.51 to 3.66]. Similar conclusions have been drawn from other retrospective studies [51,52], although it should be noted that other studies have failed to demonstrate any such association 
[53-56]. More recently, a large analysis of prescription claims data from the United States also failed to find an association between OPS use and acute kidney injury [57], although it should be recognized that cases may be underestimated in insurance databases compared to data collected from medical records.

Two reasons may be put forward to explain the relatively small numbers of declared cases of kidney injury in patients taking OPS. The first is that such cases may be undiagnosed and under-recognized if renal function tests are not performed systematically in patients receiving OPS. If only a small portion of tubules are damaged, which may typically be the case, renal impairment may be difficult to detect and ignored in certain patients The second reason may be that presence of additional risk factors may be necessary for clinically relevant kidney injury to occur and it has been recognized that many of the identified cases presented such risk factors $[19,41]$. Importantly, excessive fluid loss during the bowel cleansing process due to failure to drink sufficient water may lead to particularly high urinary concentrations of phosphate and calcium, and this seems to be a particularly critical vulnerability factor for the development of APN.

\section{Sulphate salts}

To date no episode of acute renal failure associated with APN has been reported in the literature in patents receiving OSS bowel cleansing preparations. During the clinical development program, clinically significant elevations of serum creatinine have not been reported with OSS $[28,29,58]$, including in patients with renal failure [27].

A post-marketing study of treatment-emergent adverse events (TEAEs) associated with bowel preparation and colonoscopy using OSS versus other prescription bowel preparations has been undertaken in the United States using de-identified health insurance claims data of 287,323 patients undergoing colonoscopy for bowel cancer screening [30]. In this population, 31,885 individual prescriptions for OSS were documented. The adjusted incidence of TEAEs was low $(<2 \%)$ and fewer overall, cardiac and renal events and serum electrolyte abnormalities were observed in the OSS cohort than in the non-OSS cohort.

In addition, intravenous or intramuscular administration of relatively large amounts of sulphate $(20 \mathrm{~g})$ in the form of magnesium sulphate has been practiced for over 20 years in the management of preeclampsia and is relatively well-tolerated, with no evidence of renal toxicity $[59,60]$.

\section{Conclusions}

Acute or chronic kidney injury is a well-characterized risk associated with use of OPS as bowel cleansing preparations. This is thought to arise due to perturbations of calcium and phosphate homeostasis as a result of rises in serum phosphate levels, which lead to high concentrations of calcium phosphate in the distal tubule and collecting ducts of the kidney, where it may precipitate. Although APN is rare, it may lead to permanent and, in some cases, progressive kidney damage. For this reason, the current 2013 European endoscopy guidelines recommend against routine use of OPS given that equally effective and less risky alternatives exist [6]. Notably, OSS-based bowel cleansing preparations have been developed over the last decade which are clearly superior to OPS in terms of risk. Like OPS, these have the advantage of being able to be administered in low volumes and provide a similar bowel-cleansing efficacy to PEG. There are theoretical reasons to believe that OSS solutions will not harm the kidney, based on differences in how the kidney handles sulphate and phosphate, and to date, use of OSS has not been associated with elevations in serum creatinine or other markers of renal impairment, nor with clinical manifestations of kidney injury or nephrocalcinosis. For these reasons, OSS presents clear advantages over OPS for use as routine bowel cleansing preparation. However, it should be noted that OSS has not been evaluated in patients with more severe renal disease (GFR $<30 \mathrm{~mL} / \mathrm{min}$ ) or in patients on hemodialysis. Unlike OPS, OSS is not contraindicated in patients with vulnerability factors for renal injury, although caution should be exercised when using OSS in patients with clinically significant renal, hepatic or cardiac impairment and those at risk of electrolyte imbalance. Nonetheless, experience with OSS in everyday practice is at an early stage and, as with all new medicinal products, physicians should be vigilant in detecting potential safety issues.

In conclusion, the available evidence suggests that OSS presents a more acceptable risk profile than OPS with respect to renal safety for use as low-volume bowel-cleansing preparations and has advantages over PEG-based preparations in terms of patient convenience and comfort. Given the availability of OSS, there is now no reason to use OPS-based bowel-cleansing preparations which expose patients to unnecessary risk in routine practice.

\section{Competing interests}

Thierry Ponchon has received consultancy fees from Ipsen Pharma, Olympus Co, Cook Medical, Fujifilm, Norgine and Boston Scientific, has participated in several expert boards for Olympus Co, Ipsen Pharma, Fujifilm, Cook Medical, Norgine and Boston Scientific, and has received research grants from Olympus Co, Boston Scientific, Ferring, and Fujifilm.

\section{References}

[1] von Karsa L, Patnick J, Segnan N et al. European guidelines for quality assurance in colorectal cancer screening and diagnosis: overview and introduction to the full supplement publication. Endoscopy 2013; 45 : $51-59$

[2] Barkun A, Chiba N, Enns R et al. Commonly used preparations for coIonoscopy: efficacy, tolerability, and safety - a Canadian Association of Gastroenterology position paper. Can J Gastroenterol 2006; 20: $699-710$

[3] Belsey J, Epstein O, Heresbach D. Systematic review: oral bowel preparation for colonoscopy. Aliment Pharmacol Ther 2007; 25: 373-384

[4] Wexner SD, Beck DE, Baron TH et al. A consensus document on bowel preparation before colonoscopy: prepared by a task force from the American Society of Colon and Rectal Surgeons (ASCRS), the Ameri- 
can Society for Gastrointestinal Endoscopy (ASGE), and the Society of American Gastrointestinal and Endoscopic Surgeons (SAGES). Gastrointest Endosc 2006; 63: 894 - 909

[5] Saltzman JR, Cash BD, Pasha SF et al. Bowel preparation before colonoscopy. Gastrointest Endosc 2015; 81: 781 - 794

[6] Hassan C, Bretthauer M, Kaminski MF et al. Bowel preparation for colonoscopy: European Society of Gastrointestinal Endoscopy (ESGE) Guideline. Endoscopy 2013; 45: 142 - 155

[7] Fordtran JS, Hofmann AF. Seventy years of polyethylene glycols in gastroenterology: The journey of PEG 4000 and 3350 from nonabsorbable marker to colonoscopy preparation to osmotic laxative. Gastroenterology 2017; 152: 675-680

[8] Ghandehari H, Smith PL, Ellens $\mathrm{H}$ et al. Size-dependent permeability of hydrophilic probes across rabbit colonic epithelium. J Pharmacol Exp Ther 1997; 280: 747 - 753

[9] Di Palma J, Rex D. Advances in bowel preparations: new formulation and clinical results. Gastroenterol Nurs 2011; 34 (Suppl. 02): S2 - S8

[10] Sabbagh Y, Giral H, Caldas Y et al. Intestinal phosphate transport. Adv Chronic Kidney Dis 2011; 18: 85-90

[11] Institute of Medicine. Dietary reference intakes for calcium, phosphorus, magnesium, vitamin D, and fluoride. The National Academies Press; 1997

[12] Lederer E. Regulation of serum phosphate. The Journal of physiology 2014; 592: 3985-3995

[13] Gumurdulu Y, Serin E, Ozer B et al. Age as a predictor of hyperphosphatemia after oral phosphosoda administration for colon preparation. J Gastroenterol Hepatol 2004; 19: 68-72

[14] Casais MN, Rosa-Diez G, Perez S et al. Hyperphosphatemia after sodium phosphate laxatives in low risk patients: prospective study. World J Gastroenterol 2009; 15: 5960 - 5965

[15] Lieberman DA, Ghormley J, Flora K. Effect of oral sodium phosphate colon preparation on serum electrolytes in patients with normal serum creatinine. Gastrointest Endosc 1996; 43: 467-469

[16] Ehrenpreis ED. Increased serum phosphate levels and calcium fluxes are seen in smaller individuals after a single dose of sodium phosphate colon cleansing solution: a pharmacokinetic analysis. Aliment Pharmacol Ther 2009; 29: 1202 - 1211

[17] DiPalma JA, Buckley SE, Warner BA et al. Biochemical effects of oral sodium phosphate. Dig Dis Sci 1996; 41: 749-753

[18] Caswell M, Thompson WO, Kanapka JA et al. The time course and effect on serum electrolytes of oral sodium phosphates solution in healthy male and female volunteers. Can J Clin Pharmacol 2007; 14 : e260-e274

[19] Rex DK, Vanner SJ. Colon cleansing before colonoscopy: does oral sodium phosphate solution still make sense? Can J Gastroenterol 2009; 23: $210-214$

[20] Florentin M, Liamis G, Elisaf MS. Colonoscopy preparation-induced disorders in renal function and electrolytes. World J Gastrointest Pharmacol Ther 2014; 5: 50-54

[21] Clarkston WK, Tsen TN, Dies DF et al. Oral sodium phosphate versus sulfate-free polyethylene glycol electrolyte lavage solution in outpatient preparation for colonoscopy: a prospective comparison. Gastrointest Endosc 1996; 43: 42 - 48

[22] Beloosesky Y, Grinblat J, Weiss A et al. Electrolyte disorders following oral sodium phosphate administration for bowel cleansing in elderly patients. Arch Intern Med 2003; 163: 803-808

[23] Cocchetto DM, Levy G. Absorption of orally administered sodium sulfate in humans. J Pharm Sci 1981; 70: $331-333$

[24] Cole DE, Evrovski J. The clinical chemistry of inorganic sulfate. Crit Rev Clin Lab Sci 2000; 37: 299-344
[25] Cole DE, Thurgood AM, Whiting SJ. Increased serum sulfate after protein loading in adult humans. Can J Physiol Pharmacol 1991; 69: $25-27$

[26] Hoffman DA, Wallace SM, Verbeeck RK. Circadian rhythm of serum sulfate levels in man and acetaminophen pharmacokinetics. Eur ] Clin Pharmacol 1990; 39: $143-148$

[27] Pelham RW, Alcorn H Jr et al. A pharmacokinetics evaluation of a new, low-volume, oral sulfate colon cleansing preparation in patients with renal or hepatic impairment and healthy volunteers. J Clin Pharmacol 2010; 50: $350-354$

[28] Di Palma JA, Rodriguez R, McGowan J et al. A randomized clinical study evaluating the safety and efficacy of a new, reduced-volume, oral sulfate colon-cleansing preparation for colonoscopy. Am J Gastroenterol 2009; 104: 2275-2284

[29] Rex DK, Di Palma JA, Rodriguez $R$ et al. A randomized clinical study comparing reduced-volume oral sulfate solution with standard 4-liter sulfate-free electrolyte lavage solution as preparation for colonoscopy. Gastrointest Endosc 2010; 72: 328-336

[30] Anastassopoulos K, Farraye FA, Knight T et al. A comparative study of treatment-emergent adverse events following use of common bowel preparations among a colonoscopy screening population: results from a post-marketing observational study. Dig Dis Sci 2016; 61: $2993-3006$

[31] Cheng CY, Kuro-o M, Razzaque MS. Molecular regulation of phosphate metabolism by fibroblast growth factor-23-klotho system. Adv Chronic Kidney Dis 2011; 18: $91-97$

[32] Mahon MJ. The parathyroid hormone receptorsome and the potential for therapeutic intervention. Curr Drug Targets 2012; 13: 116- 128

[33] Choi NW. Kidney and phosphate metabolism. Electrolyte Blood Press 2008; 6: 77-85

[34] Hruska KA, Mathew S, Lund R et al. Hyperphosphatemia of chronic kidney disease. Kidney Int 2008; 74: 148-157

[35] Patel V, Nicar M, Emmett M et al. Intestinal and renal effects of lowvolume phosphate and sulfate cathartic solutions designed for cleansing the colon: pathophysiological studies in five normal subjects. Am J Gastroenterol 2009; 104: 953-965

[36] Tan HL, Liew QY, Loo $S$ et al. Severe hyperphosphataemia and associated electrolyte and metabolic derangement following the administration of sodium phosphate for bowel preparation. Anaesthesia 2002; 57 : $478-483$

[37] Murer H, Markovich D, Biber J. Renal and small intestinal sodium-dependent symporters of phosphate and sulphate. J Exp Biol 1994; 196: $167-181$

[38] Walser M, Browder AA. Ion association. III. The effect of sulfate infusion on calcium excretion. J Clin Invest 1959; 38: 1404 - 1411

[39] Singh PP, Hussain F, Gupta RC et al. Effect of dietary methionine and inorganic sulfate with and without calcium supplementation, on urinary calcium excretion of guinea pigs (Cavia porcellus). Indian J Exp Biol 1993; 31: $96-97$

[40] Zipser RD, Bischel MD, Abrams DE. Hypocalcemic tetany due to sodium phosphate ingestion in acute renal failure. Nephron 1975; 14 : $378-381$

[41] Gonlusen G, Akgun H, Ertan A et al. Renal failure and nephrocalcinosis associated with oral sodium phosphate bowel cleansing: clinical patterns and renal biopsy findings. Arch Pathol Lab Med 2006; 130: 101 106

[42] Desmeules S, Bergeron MJ, Isenring P. Acute phosphate nephropathy and renal failure. N Engl J Med 2003; 349: 1006 - 1007

[43] Markowitz GS, Nasr SH, Klein P et al. Renal failure due to acute nephrocalcinosis following oral sodium phosphate bowel cleansing. Hum Pathol 2004; 35: 675-684 
[44] Markowitz GS, Whelan J, D’Agati VD. Renal failure following bowel cleansing with a sodium phosphate purgative. Nephrol Dial Transplant 2005; 20: $850-851$

[45] Weiss ], Thorp ML. Acute phosphate nephropathy: a cause of chronic kidney disease. BMJ Case Rep 2011; 3: 2011

[46] Markowitz GS, Stokes MB, Radhakrishnan J et al. Acute phosphate nephropathy following oral sodium phosphate bowel purgative: an underrecognized cause of chronic renal failure. J Am Soc Nephrol 2005; 16: $3389-3396$

[47] Harrison NM, Hjelkrem MC. Bowel cleansing before colonoscopy: Balancing efficacy, safety, cost and patient tolerance. World J Gastrointest Endosc 2016; 8: 4-12

[48] Ehrenpreis ED, Parakkal D, Semer R et al. Renal risks of sodium phosphate tablets for colonoscopy preparation: a review of adverse drug reactions reported to the US Food and Drug Administration. Colorectal Dis 2011; 13: e270-e275

[49] Brunelli SM. Association between oral sodium phosphate bowel preparations and kidney injury: a systematic review and meta-analysis. Am J Kidney Dis 2009; 53: 448-456

[50] Hurst FP, Bohen EM, Osgard EM et al. Association of oral sodium phosphate purgative use with acute kidney injury. J Am Soc Nephrol 2007; 18: $3192-3198$

[51] Khurana A, McLean L, Atkinson S et al. The effect of oral sodium phosphate drug products on renal function in adults undergoing bowel endoscopy. Arch Intern Med 2008; 168: 593 - 597

[52] Singal AK, Rosman AS, Post JB et al. The renal safety of bowel preparations for colonoscopy: a comparative study of oral sodium phosphate solution and polyethylene glycol. Aliment Pharmacol Ther 2008; $27: 41-47$
[53] Abaskharoun R, Depew W, Vanner S. Changes in renal function following administration of oral sodium phosphate or polyethylene glycol for colon cleansing before colonoscopy. Can J Gastroenterol 2007; 21: $227-231$

[54] Brunelli SM, Lewis JD, Gupta M et al. Risk of kidney injury following oral phosphosoda bowel preparations. J Am Soc Nephrol 2007; 18: $3199-3205$

[55] Russmann S, Lamerato L, Marfatia A et al. Risk of impaired renal function after colonoscopy: a cohort study in patients receiving either oral sodium phosphate or polyethylene glycol. Am J Gastroenterol 2007; 102: 2655-2663

[56] Seol DC, Hong SN, Kim JH et al. Change in renal function after sodium phosphate preparation for screening colonoscopy. World J Gastroenterol 2010; 16: $2010-2016$

[57] Layton JB, Klemmer PJ, Christiansen CF et al. Sodium phosphate does not increase risk for acute kidney injury after routine colonoscopy, compared with polyethylene glycol. Clin Gastroenterol Hepatol 2014; 12: $1514-1521$ e1513

[58] Rex DK, DiPalma JA, McGowan J et al. A comparison of oral sulfate solution with sodium picosulfate: magnesium citrate in split doses as bowel preparation for colonoscopy. Gastrointest Endosc 2014; 80: $1113-1123$

[59] Smith JM, Lowe RF, Fullerton J et al. An integrative review of the side effects related to the use of magnesium sulfate for pre-eclampsia and eclampsia management. BMC Pregnancy Childbirth 2013; 13: 34

[60] Hunter LA, Gibbins KJ. Magnesium sulfate: past, present, and future. J Midwifery Womens Health 2011; 56: 566- 574 